\title{
Microstructural Characterization and Thermal Properties of Aluminium Titanate/Spinel Ceramic Matrix Composites
}

\author{
U. ÖNEN* AND T. BOYRAZ \\ Cumhuriyet University, Metallurgy and Materials Engineering, Sivas, Turkey
}

\begin{abstract}
Spinel $\left(\mathrm{MgAl}_{2} \mathrm{O}_{4}\right)$ ceramics possesses a high melting point, high hardness, a relatively low density, excellent transmittance, a high strength, a relatively low thermal expansion coefficient, high thermal shock resistance and high chemical inertness. Aluminium titanate $\left(\mathrm{Al}_{2} \mathrm{TiO}_{5}\right)$ exhibits extremely good thermal shock resistance and low thermal conductivity coupled with good chemical resistance in molten metals. In the present work, aluminium titanate/spinel ceramics composites with different percentages of $\mathrm{Al}_{2} \mathrm{TiO}_{5}$ were prepared using powder metallurgy techniques. The microstructural, mechanical and thermal properties were characterized using X-ray diffraction, scanning electron microscopy, differential scanning calorimetry, dilatometer and hardness. Thermal shock resistance behaviour under water quenching of the as-prepared ceramics was also evaluated. Results revealed that the addition of aluminium titanate to spinel matrix improves the properties of the aluminium titanate/spinel ceramics.
\end{abstract}

DOI: $10.12693 /$ APhysPolA.125.488

PACS: 81.05.Mh

\section{Introduction}

Magnesium aluminate spinel, which is the only stable compound in the $\mathrm{MgO}-\mathrm{Al}_{2} \mathrm{O}_{3}$ system, has long been considered an important ceramic material. Many studies have reported its properties, applications and different processing methods [1]. Magnesium aluminate spinel $\left(\mathrm{MgAl}_{2} \mathrm{O}_{4}\right)$ is an excellent refractory oxide of immense technological importance as a structural ceramic. It possesses useful physical, chemical and thermal properties, both at normal and elevated temperatures. It melts congruently at $2135^{\circ} \mathrm{C}$, shows high resistance to attack by most of the acids and alkalis and has low electrical losses. Due to these desirable properties, it has a wide range of application in structural, chemical, optical, and electrical industry. It is used as a refractory in lining of steel-making furnaces, transition and burning zones of cement rotary kilns, checker work of the glass furnace regenerators, sidewalls and bottom of the steel ladles, glass furnaces and melting tanks. Synthesis and fabrication of spinel $\mathrm{MgAl}_{2} \mathrm{O}_{4}$ is known since long. A number of techniques such as conventional solid-state-reaction (SSR), sol-gel, spray drying (atomization) and organic gel-assisted citrate complexation have been extensively employed [2].

Aluminum titanate ceramics $\left(\mathrm{Al}_{2} \mathrm{TiO}_{5}\right)$ is a synthetic ceramic material of potential interest for many structural applications, owing to its high melting point, low thermal conductivity and excellent thermal shock resistance. However, a critical feature, which greatly limits the mechanical properties of polycrystalline $\mathrm{Al}_{2} \mathrm{TiO}_{5}$, is considerable intergranular microcracking, which occurs due to the high thermal anisotropy of individual grains [3].

*corresponding author; e-mail: uonen@cumhuriyet.edu.tr
In this study, binary spinel-aluminum titanate composites at various compositions were obtained and microstructural, physical, mechanical, and thermal properties were characterized.

\section{Experimental}

In this study, spinel $\left(\mathrm{MgAl}_{2} \mathrm{O}_{4}\right)$ was produced by using alumina $\left(\mathrm{Al}_{2} \mathrm{O}_{3}\right.$, Merck, Germany) and magnesia ( $\mathrm{MgO}$, technical purity), and aluminum titanate $\left(\mathrm{Al}_{2} \mathrm{TiO}_{5}\right)$ was produced by using alumina $\left(\mathrm{Al}_{2} \mathrm{O}_{3}\right.$, Merck, Germany) and titania $\left(\mathrm{TiO}_{2}\right.$, Merck, Germany) powders. Starting materials that we use are regarded as $99.9 \%$ percent pure. After the alumina and magnesia were weighed in terms of mole ratio (1:1) of spinel, with 1:1 molar ratio mixtures were dispersed in acetone and milled as wet with alumina balls of $\varnothing 10 \mathrm{~mm}$ for $3 \mathrm{~h}$. The materials containing $\mathrm{Al}_{2} \mathrm{O}_{3}$ and $\mathrm{TiO}_{2}$ were prepared in the same way by wet ball milling. $\mathrm{Al}_{2} \mathrm{TiO}_{5}$ ceramics were synthesized by reaction sintering of an equimolar mixture of $\mathrm{Al}_{2} \mathrm{O}_{3}$ and $\mathrm{TiO}_{2}$ powders. The powders were first homogenized by wet ball milling. The resulting mixtures were then sintered at $1550{ }^{\circ} \mathrm{C}$ for spinel $\left(\mathrm{MgAl}_{2} \mathrm{O}_{4}\right)$ and $1600{ }^{\circ} \mathrm{C}$ for aluminum titanate (AT) in air for $2 \mathrm{~h}$.

Then, additions of AT in weight proportions of 0,5 , $10 \mathrm{wt} \%$ were made to the spinel + aluminum titanate (SAT) mixture (hereafter these mixtures are denoted SAT0 (100\% spinel), SAT5 (95\% spinel, 5\% aluminum titanate) and SAT10 (90\% spinel, $10 \%$ aluminum titanate), respectively). Each lot was again wet mixed according to the procedure described above. Then, mixtures were pressed at $200 \mathrm{MPa}$ into $30 \times 30 \times 5 \mathrm{~mm}^{3}$ specimens. The compacts were sintered in air using a heating rate of $5^{\circ} \mathrm{C} \mathrm{min}-1$, soaked at $1700^{\circ} \mathrm{C}$. Bulk density, porosity and water absorption of the sintered samples were measured. Microhardness (Shimadzu, HMV) was measured on the polished surface of the samples at room temperature. At least six individual tests with a 
peak load of $2000 \mathrm{~g}$ and a loading time of $20 \mathrm{~s}$ were performed for each set of composites. After sample sections were mechanically polished and then thermally etched at $1500^{\circ} \mathrm{C}$ for $4 \mathrm{~h}$ in air, the microstructural characterization of the sintered samples was carried out using scanning electron microscopy (Leo 440). The morphological parameters of the various phases were characterized by using a semiautomatic image analyzer, energy-dispersive X-ray spectroscopy (EDX) and the formed phases were analyzed by X-ray powder diffractometer (Rigaku, Dmax, IIIC) using $\mathrm{Cu} K_{\alpha}$ radiation. The thermal behavior of the SAT composition was characterized by differential scanning calorimetry (DSC) (Shimadzu, DSC-60). Thermal expansion coefficients were measured by using dilatometer (Anter, USA).

\section{Result and discussion}

Table shows physical properties of the sintered SAT ceramics obtained for the different mixtures prepared. Both the bulk and true densities of the composites decreased with increasing aluminum titanate content. Note that the theoretical density of spinel is $3.58 \mathrm{~g} \mathrm{~cm}^{-3}$ whereas the density of $\mathrm{Al}_{2} \mathrm{TiO}_{5}$ is $3.20 \mathrm{~g} \mathrm{~cm}^{-3}$ [4, 5]. Also evident in Table is that the porosity and water absorption decreased with from 0 to $10 \mathrm{wt} \% \mathrm{Al}_{2} \mathrm{TiO}_{5}$ content and sintering temperature.

TABLE

Physical properties of sintered samples.

\begin{tabular}{c|c|c|c|c|c}
\hline \hline & $\begin{array}{c}\rho_{\text {bulk }} \\
{\left[\mathrm{g} / \mathrm{cm}^{3}\right]}\end{array}$ & $\begin{array}{c}\rho_{\text {true }} \\
{\left[\mathrm{g} / \mathrm{cm}^{3}\right]}\end{array}$ & $\begin{array}{c}\rho_{\text {relative }} \\
{[\%]}\end{array}$ & $\begin{array}{c}\text { Porosity } \\
{[\%]}\end{array}$ & $\begin{array}{c}\text { Water } \\
\text { absorption } \\
{[\%]}\end{array}$ \\
\hline \multicolumn{5}{c}{ Sintered at $1700{ }^{\circ} \mathrm{C}$} \\
\hline SAT0 & 3.46 & 3.58 & 96.64 & 3.352 & 0.03 \\
SAT5 & 3.45 & 3.56 & 96.91 & 3.089 & 0 \\
SAT10 & 3.44 & 3.54 & 97.17 & 2.824 & 0
\end{tabular}

Figure 1 is representative of SEM micrographs taken from the surface of the sintered SAT0, SAT5, and SAT10 samples. It can be seen that SAT10 appears to be denser and fewer pores than the sample SAT5, and SAT5 appears to be denser and fewer pores than the sample SAT0. As received, denser structure was observed with increasing aluminum titanate content. The addition of aluminum titanate also influences the grain morphology as is observed in the microstructures of the composites. The grain size is growing as the amount of aluminum titanate increases. EDX shows that microstructure of SAT10 sample was used for phase analysis. Region C consists of two main phases (spinel and $\mathrm{Al}_{2} \mathrm{TiO}_{5}$ ) because it contained $\mathrm{Mg}, \mathrm{O}, \mathrm{Al}$, and $\mathrm{Ti}$. Region $\mathrm{B}$ consists of $\mathrm{Mg}, \mathrm{O}, \mathrm{Al}$, and $\mathrm{Ti}$. Region $\mathrm{A}$ is consisting of $\mathrm{Mg}$, $\mathrm{O}, \mathrm{Al}$, and Ti. Titanium content was found as $0.58 \%$ in the general EDX analysis $(\mathrm{C}), 0.32 \%$ in within the grain structure (A) and $6.16 \%$ at the grain border (B). Hence, aluminum titanate is more intense at grain borders. The average grain size was determined as $4 \mu \mathrm{m}$ for SAT0, $7.5 \mu \mathrm{m}$ for SAT5, and $13.50 \mu \mathrm{m}$ for SAT10.

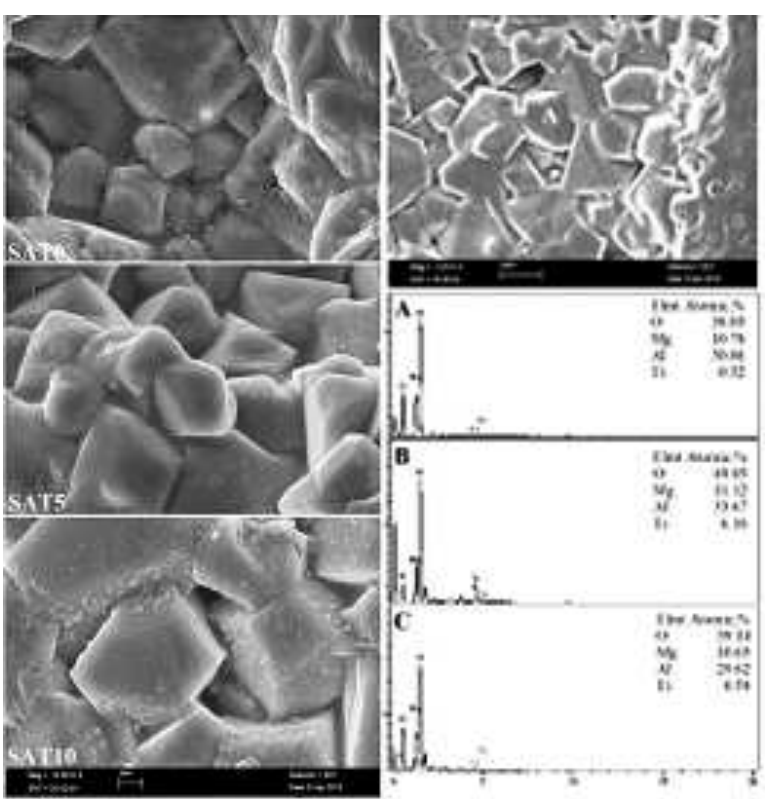

Fig. 1. Scanning electron micrographs of SAT0, SAT5, and SAT10, and EDX images analyses of SAT10.

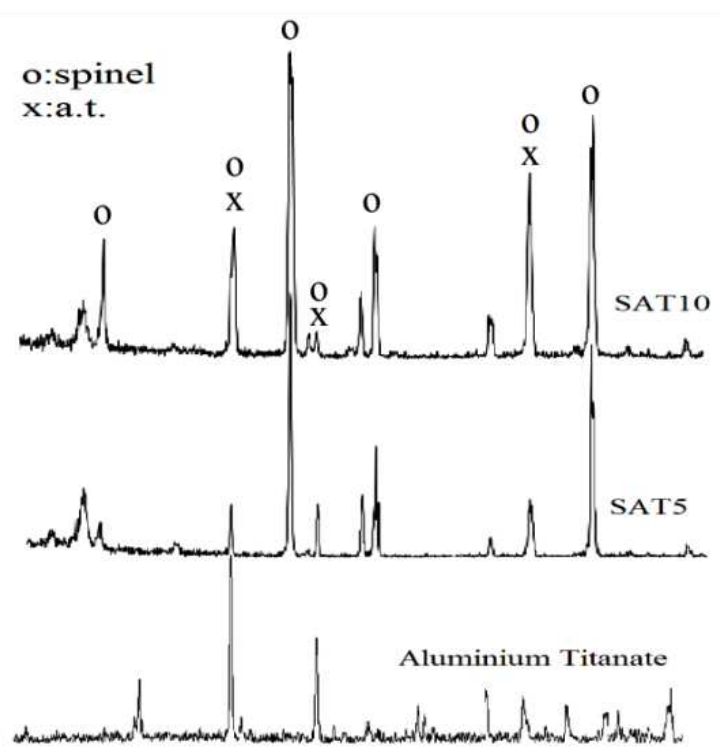

Fig. 2. XRD analyses of SAT5, SAT10, and aluminium titanate.

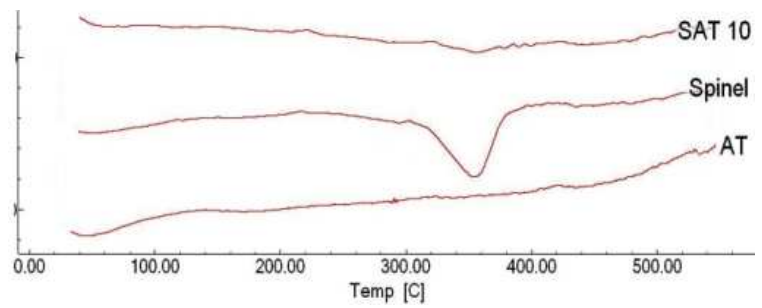

Fig. 3. DSC curves of spinel, AT and SAT10 ceramics. 


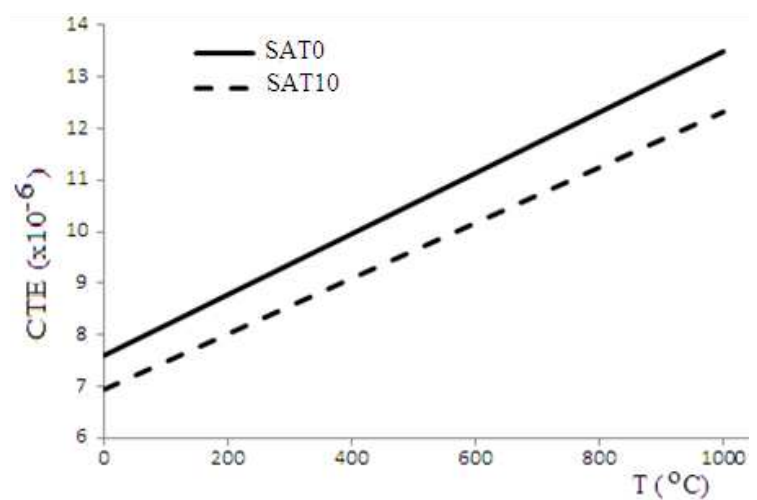

Fig. 4. Average coefficient of thermal expansion plots of SAT0 and SAT10 ceramics.

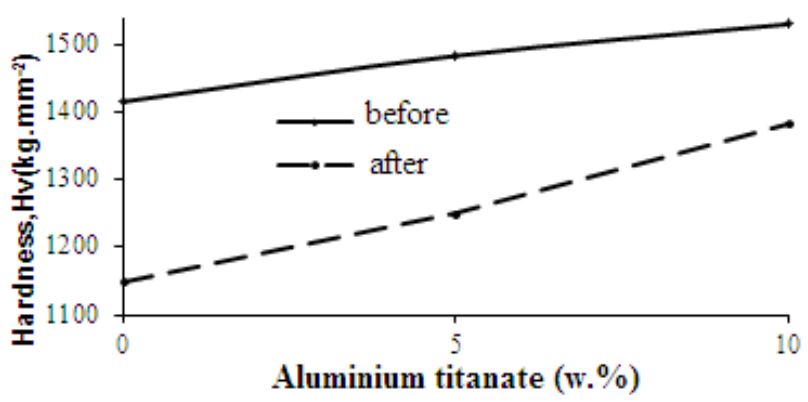

Fig. 5. Vickers microhardness SAT0 and SAT10 samples before thermal shock testing and after thermal shock testing.

The X-ray diffraction patterns of the sintered samples are shown in Fig. 2. XRD analysis of the as sintered samples revealed that main phases are spinel and aluminum titanate.

The thermal behavior of the spinel, AT and SAT10 ceramics were characterized by differential scanning calorimetry (DSC) in Fig. 3. After the initial adsorbed water loss, the spinel and SAT10 samples displayed regions of mass loss within $330-370^{\circ} \mathrm{C}$ corresponding to endothermic peaks in the DSC curve.

The thermal expansion behavior of SAT0 and SAT10 ceramics is shown in Fig. 4. SAT0 has a coefficient of thermal expansion (CTE) of $7.6 \times 10^{-6}{ }^{\circ} \mathrm{C}^{-1}$ for spinel in the range $25-1000^{\circ} \mathrm{C}[6] . \quad \mathrm{Al}_{2} \mathrm{TiO}_{5}$ has a coefficient of thermal expansion (CTE) of $1 \times 10^{-6}{ }^{\circ} \mathrm{C}^{-1}$ [7]. Addition of AT is observed to decrease the CTE of samples. Samples SAT0 and SAT10 have CTE of $7.6 \times 10^{-6}{ }^{\circ} \mathrm{C}^{-1}$ and $6.94 \times 10^{-6}{ }^{\circ} \mathrm{C}^{-1}$, respectively, in the range of $25^{-}$ $1000{ }^{\circ} \mathrm{C}$. It is well known that a low CTE is one of the requirements for improving thermal shock resistance at elevated temperatures.
Figure 5 shows microhardness of SAT0 and SAT10 samples before thermal shock testing and after thermal shock testing. Microhardness (Shimadzu, HMV) was measured on the polished surface of the samples at room temperature. At least six individual tests with a peak load of $2000 \mathrm{~g}$ and a loading time of $20 \mathrm{~s}$ were performed for each set of composites. After thermal shock testing, microhardness was measured again. The microhardness increases with increasing AT content. In the case of SAT10, the hardness has the biggest value (1530 Hv). Therefore, increasing AT content can be attributed to the mechanical properties like hardness.

\section{Conclusion}

Aluminium titanate/spinel ceramics with different percentages of $\mathrm{Al}_{2} \mathrm{TiO}_{5}$ was prepared, microstructural and thermal properties were characterized. More denser and fewer pores structure was observed with increasing aluminum titanate content. The addition of aluminum titanate also influences the grain morphology as is observed in the microstructures of the composites. The grain size is growing as the amount of aluminum titanate increases. Spinel-AT ceramic composites show increased hardness depending upon the AT content. Sample SAT0 has a hardness of $1415 \mathrm{Hv}$, which increases further to $1530 \mathrm{Hv}$ on addition of $10 \mathrm{wt} \%$ AT. Finally, the hardness increased as aluminum titanate content increased. XRD analysis of the sintered samples revealed that main phases are spinel and aluminum titanate $\left(\mathrm{Al}_{2} \mathrm{TiO}_{5}\right)$. The CTE of the spinel decreased as AT was added into it. Samples SAT0 and SAT10 have CTE of $7.6 \times 10^{-6}{ }^{\circ} \mathrm{C}^{-1}$ and $6.94 \times 10^{-6}{ }^{\circ} \mathrm{C}^{-1}$, respectively, in the range $25-1000^{\circ} \mathrm{C}$. It is well known that a low CTE is one of the requirements for improving thermal shock resistance at elevated temperatures.

\section{References}

[1] H. Reverón, Mater. Lett. 56, 97 (2002).

[2] L.R. Ping, Mater. Res. Bull. 36, 1417 (2001).

[3] H.A.J. Thomas, R. Stevens, Br. Ceram. Trans. J. 88, 184 (1987).

[4] E.Y. Sako, M.A.L. Braulio, Ceram. Int. 38, 2243 (2012).

[5] H. Gökçe, T. Boyraz, Z. Keçeli, M.L. Öveçoğlu, O. Addemir, in: 2nd International World Congress on Ceramics, International Ceramics Federation (ICF), Verona 2007, p. 56.

[6] C. Aksel, J. Europ. Ceram. Soc. 24, 2839 (2004).

[7] I.M. Low, D. Lawrens, J. Am. Ceram. Soc. 88, 2957 (2005). 